University of New Hampshire

University of New Hampshire Scholars' Repository

$6-25-2020$

\title{
I'll be dammed! Public preferences regarding dam removal in New Hampshire (Pre-print)
}

\author{
Natallia Leuchanka Diessner \\ University of New Hampshire, nhe4@wildcats.unh.edu \\ Catherine Ashcraft \\ University of New Hampshire, catherine.ashcraft@unh.edu \\ Kevin H. Gardner \\ University of New Hampshire, kevin.gardner@unh.edu \\ Lawrence C. Hamilton \\ University of New Hampshire, lawrence.hamilton@unh.edu
}

Follow this and additional works at: https://scholars.unh.edu/nh_epscor

\section{Comments}

This is a pre-print of an article published by University of California Press in Elementa: Science of the Anthropocene in 2020, available online: https://dx.doi.org/10.1525/elementa.003

\section{Recommended Citation}

Diessner, Natallia Leuchanka; Ashcraft, Catherine; Gardner, Kevin H.; and Hamilton, Lawrence C., "I'll be dammed! Public preferences regarding dam removal in New Hampshire (Pre-print)" (2020). Elementa: Science of the Anthropocene. 16.

https://scholars.unh.edu/nh_epscor/16

This Article is brought to you for free and open access by the Research Institutes, Centers and Programs at University of New Hampshire Scholars' Repository. It has been accepted for inclusion in New Hampshire EPSCoR by an authorized administrator of University of New Hampshire Scholars' Repository. For more information, please contact Scholarly.Communication@unh.edu. 


\title{
I'll be dammed! Public preferences regarding dam removal in New Hampshire
}

Natallia Leuchanka Diessner ${ }^{1 *}$, Catherine M. Ashcraft ${ }^{1}$, Kevin H. Gardner ${ }^{2}$, Lawrence C. Hamilton $^{3}$

${ }^{1}$ Department of Natural Resources and the Environment, University of New Hampshire, Durham, New Hampshire, United States of America

${ }^{2}$ Department of Civil and Environmental Engineering, University of New Hampshire, Durham, New Hampshire, United States of America

${ }^{3}$ Department of Sociology, University of New Hampshire, Durham, New Hampshire, United States of America

*Corresponding Author's email address: nhe4@wildcats.unh.edu

\begin{abstract}
Decisions about dams, like other environmental conflicts, involve complex tradeoffs between different water uses with varying human and ecological impacts, have significant impacts on public resources and involve many stakeholders with diverse and often conflicting interests. Given the many upcoming dam decisions in New England and across the United States of America, an improved understanding of public preferences about dam decisions is needed to steward resources in the public interest. This research asks (1) What does the public want to see happen with dams?, and (2) Do demographic factors influence public preferences for dam decisions? This paper analyzes data from three statewide public opinion polls conducted in New Hampshire over 2018 using univariate, bivariate and multivariate statistical analysis of public preferences for dam removal or maintaining dams for specific benefits, including property values, hydropower generation, industrial history and recreation, and evaluates the effect of age, level of formal education, gender and political party.
\end{abstract}

Our findings indicate that a majority of New Hampshire residents prefer to keep dams when they are used to generate hydropower, whereas majorities prefer instead to remove dams rather than to keep them for industrial history, recreation, or property values. Respondent demographic characteristics and political outlooks influence these preferences, in patterns broadly resembling those for many other environment-related issues. Political party, gender, and age are the strongest predictors: liberal leaning, younger, and female respondents are more likely to support dam removal. Level of formal education has no significant effect on preferences for keeping or removing dams. The results provide the first insights into statewide public preferences about dam removal in New England, support the use of public opinion polling to complement input from public meetings and guide decisions, and contribute to existing scholarship about public environmental preferences and the influence of demographic factors.

\section{Introduction}

Decisions about dams, whether to build dams, modify dams or remove dams, are fundamentally decisions about managing trade-offs between different water uses with varying human and ecological impacts and, therefore, feature many of the characteristics of other environmental 
conflicts (Gleick, 2018). Dam decisions involve complex tradeoffs specific to each river system (Roy et al., 2018; Song et al., 2018), have significant impacts on public resources and involve many stakeholders with diverse and often conflicting interests (Fox et al., 2016). Dam removal proponents cite the benefits of removal for public safety, restoring fish habitat and overall ecosystem health (Mullens and Wanstreet, 2010; Fox et al., 2016; Magilligan et al., 2017). Those seeking to preserve dams cite, for example, the importance of historical preservation, aesthetics and identity. While removing dams, especially small dams, is an increasingly popular option for ecosystem restoration in New England and the United States of America (U.S.) (O'Connor et al., 2015; Magilligan et al., 2016), each dam decision is unique and many dam owners decide to keep their dam. Regardless of the final outcome, dam decisions often take many years to resolve, particularly if stakeholders feel the process has been unfair and their voice has not been heard (Magilligan et al., 2017). Given the many upcoming dam decisions in the New England region and across other parts of the U.S., an improved understanding of public preferences about dam decisions is needed to inform the public and guide communities, regulators and other stakeholders seeking to steward resources in the public interest (Johnson and Graber, 2002; Magilligan et al., 2016).

New England, and New Hampshire in particular, are dominated by dammed landscapes and ecosystem functions that have been impacted by dams for hundreds of years. Dams in the region are also known for their historic significance and influence on local economies and unique town character. Because dam issues cross spatial and temporal scales and disciplinary boundaries, interdisciplinary approaches are needed to further understand decisions around dams, particularly as they are driven by public attitudes and opinions (Magilligan et al., 2017). For example, scientists call for a more "balanced" and "informed" approach to decisions about dams, where various socioeconomic and environmental trade-offs are assessed (e.g. risk of collapse, historical significance, environmental impact) via interdisciplinary research approaches, and the findings are then used to inform stakeholder dialogue and decision-making (Roy et al., 2018). Scholars also note that more research is needed to better guide decisions about dams, such as understanding how dammed landscapes are valued at different scales (Roy et al., 2018).

Given the increased complexity of contemporary problems (Rittel and Webber, 1973), diverse stakeholders, often with conflicting worldviews, and the public demand increased participation in environmental governance and natural resource management decisions (McCool and Guthrie, 2001; Batie, 2008; Miller et al., 2014). Dam decisions typically involve a variety of public participation opportunities tailored to the goals of citizen involvement, context, previous conflict, problem, and available resources. Public participation opportunities can range from one-way interactions that seek to inform the public to two-way interactions for listening to and consulting with the public, involving and engaging the public in collaborative problem solving, or empowering the public through consensus building and shared agreements (Arnstein, 1969; Creighton, 2005; Hage et al., 2010; Clark et al., 2016). Town-hall style public meetings are the primary forums in New Hampshire for engaging stakeholders and the broader public in dam decisions (Magilligan et al., 2017). However, such public meetings are frequently held on weekday evenings, last several hours, and can be inaccessible to many residents, so they often have low attendance. As a result, as Fishkin (2011) observes, "The lack of diversity among 
those deliberating can, in itself, be a limitation on the quality of deliberation" (Fishkin, 2011). Public meetings can therefore allow small numbers of motivated people to have outsized influence over dam decisions (Magilligan et al., 2017), leaving public officials to discern and represent the public interest with very little information about the general public's actual preferences for removing dams or maintaining dams. Outside the public participation opportunities of public meetings and meetings between stakeholders and public officials, little is known about public preferences on the regional and statewide scales in New England (Mullens and Wanstreet, 2010; Opperman et al., 2011; Fox et al., 2016).

Public surveys can contribute information to better understand stakeholder and public perspectives, and more specifically, fill in gaps in understanding that are left with the frequently mandated, in-person public meetings. One of the major benefits of using surveys is that they provide a "quantitative or numeric description of trends, attitudes, or opinions of a population by studying a sample of that population" (Creswell, 2014). Another advantage of using surveys, is that they tend to have a quick turnaround time, provide a cost-efficient dataset, and are convenient (Creswell, 2014). Survey drawbacks include data and outputs less rich than other methods that go beyond simply gathering information at a single point in time and instead focus on collaborative problem solving (Creighton, 2005; Fishkin, 2011); requiring more upfront costs; and being less participatory (but perhaps more representative) than other methods of engagement involving deliberation (e.g. focus groups, workshops, etc.). Surveys can therefore be seen as tools to achieve "functional" participation, which aim to gather diverse perspectives and values surrounding an issue, and can therefore complement a deliberative participatory process (Renn and Schweizer, 2009).

An important research question that follows is, "What does the broader population want to see happen with dams?" To provide insight into public preferences for dam decisions, the survey questions in this research reflect arguments commonly heard in New England against and for dam removal. Based on an analysis of 36 interviews in New England conducted as part of the National Science Foundation-funded Future of Dams project, common arguments include generating hydropower, flatwater recreation, maintaining waterfront property values, preserving industrial history, and providing benefits for fish and wildlife (Diessner and Ashcraft, n.d.).

The case of Durham's Oyster River Dam at Mill Pond, which deals specifically with the proposition of either keeping or removing the dam, is a typical one in New England. What makes this case representative is that it exhibits a common pattern associated with dam decisions in New England, particularly where dam removal is a probable alternative for the dam in question and engaged individuals voice arguments for keeping the dam. 170 residents (out of a population of roughly 15,000) attended a 2009 public hearing about the Oyster River Dam at Mill Pond in the Town of Durham, New Hampshire. While that number may seem unusually high for a public hearing in a small, New England town, most of the attendees opposed removal of this dam (Magilligan et al., 2017). Arguments to preserve the dam for historic significance, symbolic value and hydropower potential prevailed over ecological arguments in favor of dam removal (Magilligan et al., 2017). However, it is not known how representative the viewpoints expressed at the meeting were of the residents of the Town of Durham. If the Town ultimately decides to 
preserve the town-owned dam, Durham residents will have to pay to repair the dam. If the Town decides to remove the dam, the project will be eligible for state and federal funding to supplement Town resources. As of this writing more than 10 years after the public hearing, a final decision on the future of the Mill Pond dam is yet to be made. Similarly, other communities across New Hampshire and New England are struggling over decisions regarding their dammed landscapes (Fox et al., 2016). Whatever decision is made in Durham and other communities, the decision will be expensive and implementation will involve substantial public funding, time and effort of public officials, and impacts to public natural resources. For example, in New Hampshire, water flowing by or through a property and fish, wildlife, and marine resources are held in trust by the state and stewarded for the benefit of the public (The General Court of New Hampshire, Fish and Game Commission, 2004; NH Department of Environmental Services, 2008). In addition, public opinion and perspectives can have significant outcomes not just on municipally owned dams, but also on state or privately-owned dams in New Hampshire and throughout New England (Magilligan et al., 2017). Understanding public preferences about dams at the state scale can therefore provide a broader context to complement input from public meetings and help inform public officials' decisions about dams.

The process of decision-making around dams is often a complex and contentious one, involving numerous diverse actors, issues, values, and positions. To manage social, economic and ecological benefits while reducing adverse impacts, it is necessary to further explore how the public engages in dam decision-making processes. While public meetings are necessary forums for informing the public and gathering input, public opinion polls can complement public meetings by offering insights into the opinions of the broader community and, arguably, a more representative population.

A second important research question is, "Do demographic factors influence public preferences for dam decisions?" Although we have a substantial body of research showing how public opinions on many environment-related issues are influenced by demographic factors, and especially by ideology or political identity (McCright and Xiao, 2014; Sovacool et al., 2018; Hamilton et al., 2019), there has been little comparable research on views about dam removal. Because dam decisions tend to be highly contentious (Fox et al., 2016), it is valuable to consider how demographic factors underlie their controversies.

Demographic factors addressed in this paper were selected based on decades of research on "the social bases of environmental concern," which has established that a handful of demographic characteristics - principally age, gender, education, and ideology or political identity — predict individual views on a wide range of environment-related topics (Van Liere and Dunlap, 1980; Jones and Dunlap, 1992; Guagnano and Markee, 1995; Klineberg et al., 1998; Dunlap et al., 2001; Dietz et al., 2005; Xiao and McCright, 2007). Place characteristics involving the local economy, history, or geography may be influential as well, in addition to, but not suppressing, individual demographic effects (Hamilton et al., 2010; Hamilton et al., 2015). Analyses with our dams survey questions detected these general patterns as well, with significant effects from one or more of the demographic predictors (especially, political identity) for every dam question, but only intermittent effects from geographic region. Several additional background variables that 
might conceivably predict dam opinions (e.g., years resident; news preferences) were tested as well, but showed no explanatory power; for parsimony, these are not retained in our final models.

This paper provides the first insights into statewide public preferences about dam removal, as compared to maintaining dams for specific purposes, in New England, focusing on New Hampshire. First, the regional background and telephone survey are described. Then, the results are presented from three representative surveys of public opinion regarding dam decisions in New Hampshire using univariate, bivariate and multivariate statistical methods to investigate the effects of age, education, gender and political party. Finally, we discuss how our findings provide new insights into public perceptions about balancing dam management alternatives, and particularly how these vary with respondent demographic characteristics.

\section{Dam decisions in the New England context}

As in many other places, the history and cultural identities of New England communities are intertwined with the use and development of the rivers that run through them, which have been substantially reshaped by dams. Native Americans built the first intentional dams in New England out of wood and stone to harvest fish (Goodby et al., 2014). European colonists built dams for irrigation and to power mills, sometimes on sites previously dammed by beavers or dammed, farmed or fished by Native Americans (Cronon, 2003). Later, larger dams were built to harness New England's rivers to generate power and then electricity for the factories and mills of the industrial revolution. Dam construction continued in the $19^{\text {th }}$ and $20^{\text {th }}$ century to provide myriad benefits to people and industry, including ice production, drinking water, flood control, hydropower generation, fishing and recreation. The legacy of efforts to control New England's waters is that there are over 14,000 dams throughout the region (Gold et al., 2016; Magilligan et al., 2016), some of which were originally built in the 1800s and are over 200 years old (Mullens and Wanstreet, 2010; Magilligan et al., 2016). Significant changes to the morphology, habitat and processes of the region's rivers have resulted.

For example, New Hampshire, a state located in a region with the highest density of dams in the U.S. (Graf, 1999; Magilligan et al., 2017), has between 2,000 and 3,000 active dams (Lindloff, 2003; NH Department of Environmental Services, 2008; Data Discovery Center, 2019), which does not count at least 1,500 additional dams excluded from state or federal regulatory jurisdiction because of factors such as their small size or breached condition (Lindloff, 2003). While many dams are clustered in New Hampshire's southern and seacoast area, others are scattered throughout the state (Figure 1). Currently, about $77 \%$ of the state's active dams are privately owned, $13 \%$ are owned by municipalities, $9 \%$ by the state, $1 \%$ by the federal government and fewer than $1 \%$ are owned by utility companies (NH Department of Environmental Services, 2008). 


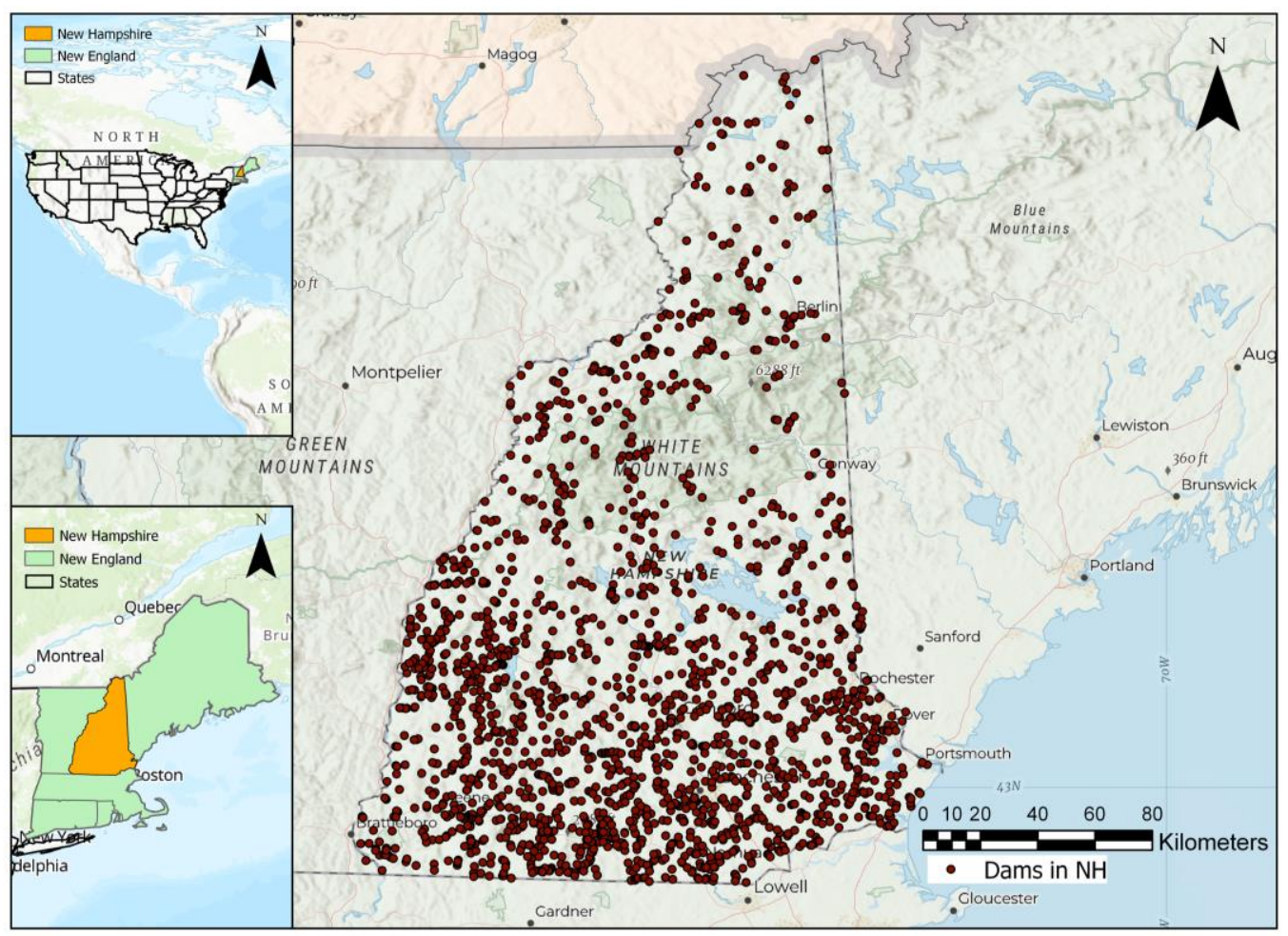

Figure 1. Dams in New Hampshire (shown in burgundy dots), a state in the New England region of the northeastern United States of America.

The map's geographical coordinate system is WGS 1984, produced with ArcGIS Pro. NH dams are from the Data Discovery Center dataset and the U.S. states from the ArcGIS repository (Hosseini Shakib, 2019).

Today, New England's dams and their impoundments provide open landscapes in an otherwise heavily forested landscape, habitat for ecological communities, opportunities for slow water recreation, and hydropower and clean energy credits for companies looking to diversify their energy sources. The dams and their impoundments also fragment river systems, blocking the movement of sediment, nutrients, and ability of fish and other wildlife to access habitat. Only $3 \%$ of the total river length in New England remains completely unobstructed and accessible to sea run fish (Roy et al., 2018). Some impoundments behind dams have elevated water temperature and poor water quality. Throughout the region, many fish populations have declined (Born et al., 1998; Poff and Hart, 2002; Limburg and Waldman, 2009; Burroughs et al., 2010; Magilligan et al., 2016). Some dams no longer meet regulatory requirements to ensure safety and require costly maintenance to stabilize their structure (Born et al., 1998; Magilligan et al., 2016). To some people the region's dams are markers of the region's industrial history (Magilligan et al., 2016), but to others the dams are markers of colonization that disrupt Native American cultural connections to the river (Opperman et al., 2011).

Decisions about what to do about dams reflect the many positive and negative impacts of dams and, like other environmental conflicts, are often contested by stakeholders with diverse 
interests. Commonly heard arguments in favor of maintaining dams include preserving cultural identity and sense of place, preserving industrial history, conserving the environment created by the dam, protecting waterfront property values, maintaining pond and lake-based recreation and generating hydropower (Fox et al., 2016; Magilligan et al., 2017; Diessner and Ashcraft, n.d.). In contrast, commonly heard arguments in favor of removing dams include restoring ecosystems, connectivity and fish populations, while also improving safety, and reducing liability and cost to owners (Opperman et al., 2011; Fox et al., 2016; Magilligan et al., 2017; Dowley et al., 2019).

Research analyzing conflict and social aspects of dam decisions, and dam removal in particular, in New England has mostly been case-specific, qualitative studies, which provide place-based perspectives not intended to represent the perspectives of the general public at a broader scale (Fox et al., 2016; Magilligan et al., 2017). Surveys of public preferences regarding dams in New England have analyzed the willingness-to-pay of demographically representative populations (Mullens and Wanstreet, 2010) at local scales, either related to specific dams or municipalities. In comparison to case studies, such surveys study a representative sample of the population to provide a quantitative description of how the total population perceives a particular issue (Creswell, 2014), but lack the context-rich analysis of qualitative case studies. However, so far as we know no research in New England has surveyed public opinion at the statewide scale, which, in addition to local and national scales, is relevant for many decision-makers involved in stewarding dams and river systems in the public interest (Magilligan et al., 2017). In addition to informing the stewardship of public resources in the public interest, better understanding public preferences around dams in the New England region is also particularly important because, unlike conflicts over other resources (e.g. forest use), conflicts over dam removal in New England is less about the "control over resources" and more about the public's perceived loss of and decreased access to their cultural identity and community-based stewardship of their local dammed landscape (Fox et al., 2016).

\section{Materials and methods}

\section{Data collection}

Survey data for this study were obtained by adding dam-related questions to the Granite State Poll (GSP), a quarterly telephone survey of New Hampshire residents carried out by the Survey Center at the University of New Hampshire. Random sampling of cell and landline telephone numbers, combined with random selection of adults within households, yield representative surveys of about 500 respondents in each GSP cycle. GSP data have been widely used for political polling (Scala and Smith, 2008) as well as basic research (Hamilton et al., 2016; Bolin and Hamilton, 2018). For a variety of general environment-related topics, New Hampshire survey responses resemble those of nationwide surveys, as shown for example in comparisons of climate-change and renewable-energy views across dozens of different surveys (Hamilton et al., 2019), or of many different global-change knowledge and opinion responses (Hamilton, 2016).

Dam removal questions were included in the GSP in February, April, and August of 2018, involving a total of 1,582 respondents. Other questions on these polls include a mix of opinion 
items and respondent background characteristics. Trained and supervised interviewers at the UNH Survey Center conducted all interviews according to specific protocols (UNH Survey Center, 2020a, b, c). To ensure sampling consistency and reduce respondent selection bias, interviewers asked to speak with the adult living in the household with the most recent birthday. If that randomly selected individual was not home at the time of the call, interviewers made an appointment to call back.

Two questions specific to dam decision alternatives were included as part of the February 2018 GSP, four (one a duplicate from February) in the April 2018 GSP, and four (all duplicates from April) in the August 2018 GSP (Diessner, Ashcraft, Gardner, and Hamilton, 2019, 2019a, 2019b). The question from the February 2018 poll was exploratory and prompted respondents to think about the tradeoffs of removing dams as opposed to keeping them for electricity generation. To better understand public preferences around other common tradeoffs associated with New England's dams, three additional tradeoffs were explored in the April 2018 poll, and all four tradeoffs were replicated in the August 2018 poll.

Table 1 gives the wording of these questions, along with probability-weighted response percentages and coding used for later analysis. In addition to question details, Table 1 provides descriptive information and coding of respondent background characteristics (age, sex, education and political party), which were chosen based on those found by prior studies to predict views on other environment-related topics (Van Liere and Dunlap, 1980; Jones and Dunlap, 1992; Hamilton and Saito, 2015), including climate change (Hamilton, 2012; Hamilton et al., 2015). If respondents associate dams with environment-centered issues, then these same background characteristics may play a role in predicting public preferences on dam decision alternatives in New Hampshire.

Survey response rates were calculated according to the American Association of Public Opinion Research Response Rate 4 definition (Gierisch et al., 2010) and were determined to be $18 \%$ for the February poll, 19\% for the April poll, and 17\% for the August poll. Sampling weights are applied in Table 1 and all other analyses in this paper to improve accuracy in representing the state's population. 


\section{Table 1. Variable definitions, with coding used for regression modeling.}

Dam decision alternative question 1 (rotated question and response order) $(n=1,582)$

Damhydro: In your opinion, is it more important to use dams on New Hampshire rivers and streams to generate electricity or

is it more important to remove dams and allow free-flowing rivers that benefit fish and wildlife? (rotated response order)

Use dams to generate electricity (coded $1 ; 46 \%$ )

Remove the dams and allow free-flowing rivers (coded 2; 33\%)

Don't Know/No Answer (DK/NA) (coded 3; 21\%)

Dam decision alternative question 2 (rotated question and response order) $(n=1,016)$

Damhis: In your opinion, is it more important to keep dams in place on New Hampshire rivers and streams in order to preserve New Hampshire's industrial history, or is it more important to remove the dams and allow free-flowing rivers that benefit fish and wildlife?

Keep dams to preserve New Hampshire's industrial history (coded 1;29\%)

Remove the dams and allow free-flowing rivers (coded 2; 52\%)

Don't Know/No Answer (DK/NA) (coded 3; 19\%)

Dam decision alternative question 3 (rotated question and response order) ( $n=1,016)$

Damrec: In your opinion, is it more important to keep dams in place on New Hampshire rivers and streams in order to preserve recreational opportunities in lakes and ponds, or is it more important to remove the dams and allow free-flowing rivers that benefit fish and wildlife?

Keep dams to preserve recreational opportunities (coded 1; 37\%)

Remove the dams and allow free-flowing rivers (coded $2 ; 43 \%$ )

Don't Know/No Answer (DK/NA) (coded 3; 20\%)

Dam decision alternative question 4 (rotated question and response order) $(n=1,016)$

Damprop: In your opinion, is it more important to keep dams in place on New Hampshire rivers and streams in order to preserve waterfront property values, or is it more important to remove the dams and allow free-flowing rivers that benefit fish and wildlife?

Keep dams to preserve waterfront property values (coded $1 ; 27 \%$ )

Remove the dams and allow free-flowing rivers (coded $2 ; 54 \%$ )

Don't Know/No Answer (DK/NA) (coded 3; 19\%)

Respondent background characteristics

Gender: Male (coded 0; 49\%) or female (coded 1; 51\%)

Age: What is your current age? (mean 50, SD 18, range 18-96)

Age Group:

18-29 (coded $1 ; 20 \%)$

$30-39($ coded $2 ; 14 \%)$

$40-49$ (coded $3 ; 15 \%)$

$50-64$ (coded $4 ; 31 \%)$

$65+($ coded $5 ; 20 \%)$

Education: What is the highest grade of education you completed and got credit for?

High school or less (coded $-1 ; 27 \%$ )

Technical school or some college (coded $0 ; 41 \%)$

College graduate (coded $1 ; 20 \%$ )

Postgraduate work (coded 2; 12\%)

Party: Generally speaking, do you usually think of yourself as a Republican, a Democrat, an Independent or what?

Democrat (coded $-1 ; 43 \%$ )

Independent (coded $0 ; 19 \%)$

Republican (coded $1 ; 38 \%)$

Survey responses shown in codes used for modeling, and with probability-weighted percentages or means (February 2018 poll

$n=566$; April 2018 poll $n=515$; August 2018 poll $n=501$ ) 
The Institutional Review Board for the Protection of Human Subjects in Research (IRB) at the University of New Hampshire approved this study (IRB \#3259). Oral consent was obtained for all study participants.

\section{Data analysis}

Univariate statistics were used to derive a basic understanding of respondents' preferences and of whether New Hampshire residents generally tend to support dam removal. To understand how results vary by respondent characteristics and to be able to predict preferences by demographics, we used a combination of binomial and multinomial logit regression models. Binomial logit regression (responses dichotomized into support for dam removal versus all other answers) was used to test simple relationships between the dependent variables (support for dam removal under each tradeoff) and, separately, each of the independent variables describing background characteristics (age, sex, education, and political party). Preliminary analysis and visualizations of bivariate results appear in an earlier paper by Leuchanka et al. (2019). The present paper provides a more detailed bivariate analysis, followed by multivariate analysis with all background variables considered together, and the full range of dam question responses.

Our dam-removal questions each offered three response choices: remove dams, keep dams [for reason], or don't know. Many people gave "don't know" responses; to analyze these as distinct from the remove-dams and keep-dams responses, our multivariate analysis employs multinomial logit modeling - a method appropriate for analysis of dependent variables that have multiple unordered categories (Hamilton, 2012; Hamilton, 2013). This approach models the odds of respondents favoring one outcome over another (e.g. keep dams for hydropower vs. remove) as a multiplicative function of one or more independent (exogenous) variables, such as respondent background characteristics. Relative risk ratios (RRR), analogous to the odds ratios of binary logit models, describe multiplicative effects of a one-unit increase in a given predictor, on the odds favoring a given category of $y$ compared with the base category of $y$. Risk ratios below 1 correspond conceptually to negative effects in linear regression; ratios above 1 correspond to positive effects.

\section{Results}

\section{Univariate results}

Specific questions explored tradeoffs associated with keeping dams for specific purposes versus removing dams for benefits to fish and wildlife derived from free-flowing rivers. Weighted response percentages to the questions in Table 1 are also charted in Figure 2. 


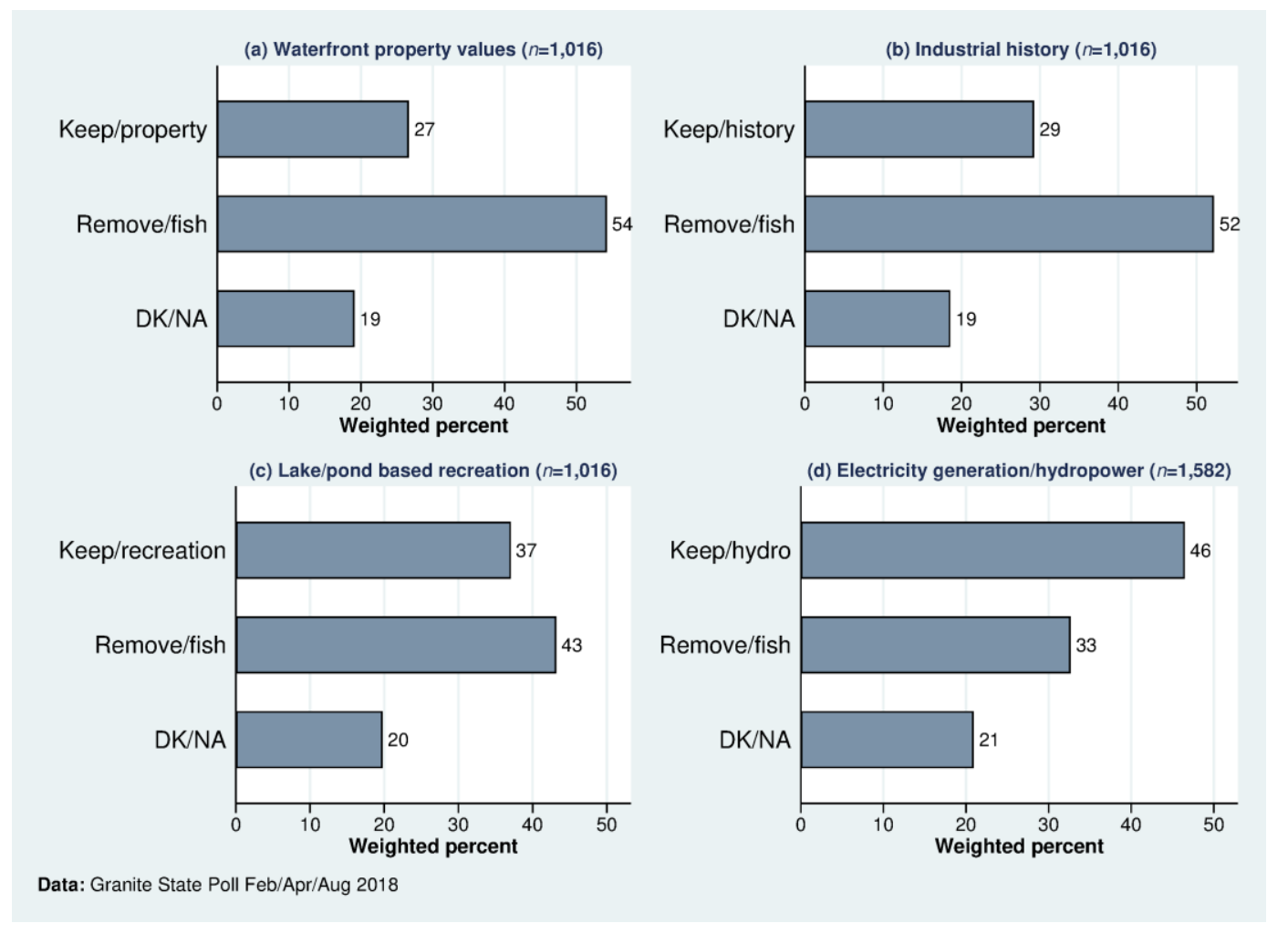

Figure 2. Dam alternative preferences by tradeoff.

Sorted by preference for dam removal to allow free-flowing rivers that benefit fish and wildlife as opposed to keeping dams to (a) maintain waterfront property values; (b) preserve industrial history; (c) maintain lake- and pond-based recreation; and (d) generate electricity (from hydropower).

Responses indicate that more people prefer dam removal when the purpose for keeping dams is to maintain waterfront property values (Figure 2a; damprop) or preserve New Hampshire's industrial history (Figure $2 \mathrm{~b}$; damhis). Over $50 \%$ of respondents indicated that their preference would be to remove dams when the alternative is to keep them for historic presentation. Only $29 \%$ of respondents preferred keeping dams when historic preservation (damhis) was the associated tradeoff. Similar results are seen in the question exploring waterfront property values (damprop), with half the respondents preferring removal and less than a third preferring to keep dams. Although more people prefer to remove dams as opposed to keeping them for lake- and pond-based recreation (Figure 2c; damrec), the difference between these two management preferences is not as striking as that seen in other questions in this survey (with only $6 \%$ more people preferring removal over keeping dams), with $43 \%$ of respondents supporting dam removal and $37 \%$ keeping dams for recreation (Figure 2c). In the question exploring tradeoffs around hydropower (Figure 2d; damhydro), a greater percentage of New Hampshire residents (46\%) prefer keeping dams, as compared to removing them (33\%). Approximately one fifth of respondents were unsure (responded either "don't know" or provided no answer) about their preference for dam removal across all four questions. 


\section{Bivariate relationships}

\section{Waterfront property values}

Political party and age are the two strongest predictors of whether people support dam removal, rather than keeping dams to protect property values (damprop). Younger respondents (under the age of 65) and Democrats (63\%) tend to support removal when the alternative is to keep dams to maintain property values (Figure 3). Gender and education make little difference regarding this question: majorities of men and women, or with any level of education beyond high school, tend to support removal.

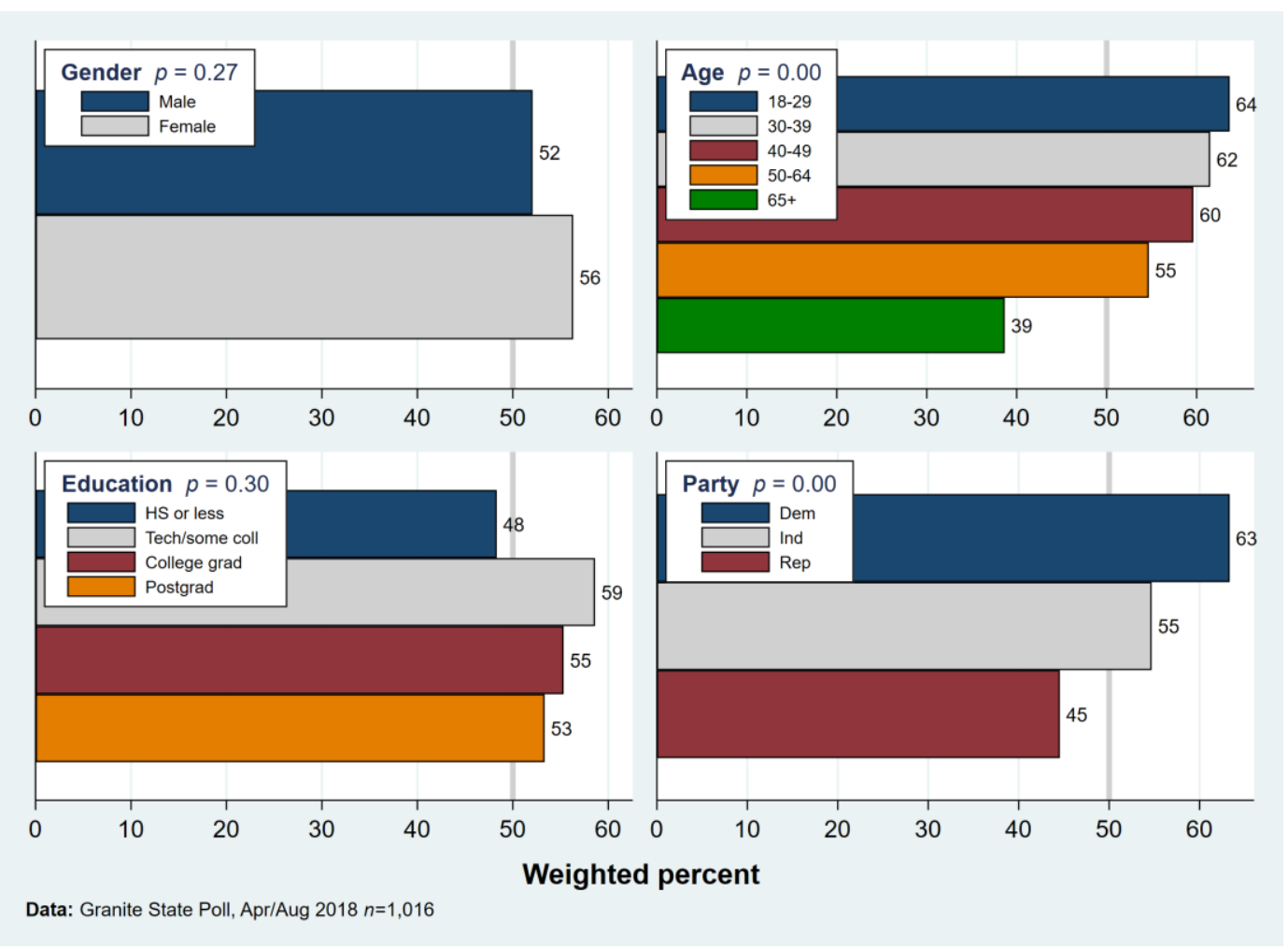

Figure 3. Respondents who prefer dam removal for benefits of fish and wildlife, over those want to keep dams for maintaining waterfront property values and those who responded don't know or gave no answer (dichotomized dependent variable).

Preferences to remove dams are broken down by respondent characteristics. $p$ values represent probabilities from $F$ tests for null hypothesis of predictors having no association with pro-dam removal responses.

\section{Preservation of industrial history}

Age and party again make the most difference when it comes to preferring dam removal over keeping dams for preservation of industrial history (damhis; Figure 4). Differences by gender and education are not significant. Older respondents, particularly those over the age of 65 , are less likely to prefer dam removal if the alternative is to keep dams to preserve their historic 
significance, with only $42 \%$ selecting removal as the preferred alternative. Political party is also a strong predictor, with Democrats (59\%) and independents $(57 \%)$ supporting dam removal (59\%) compared with just $43 \%$ among Republicans.
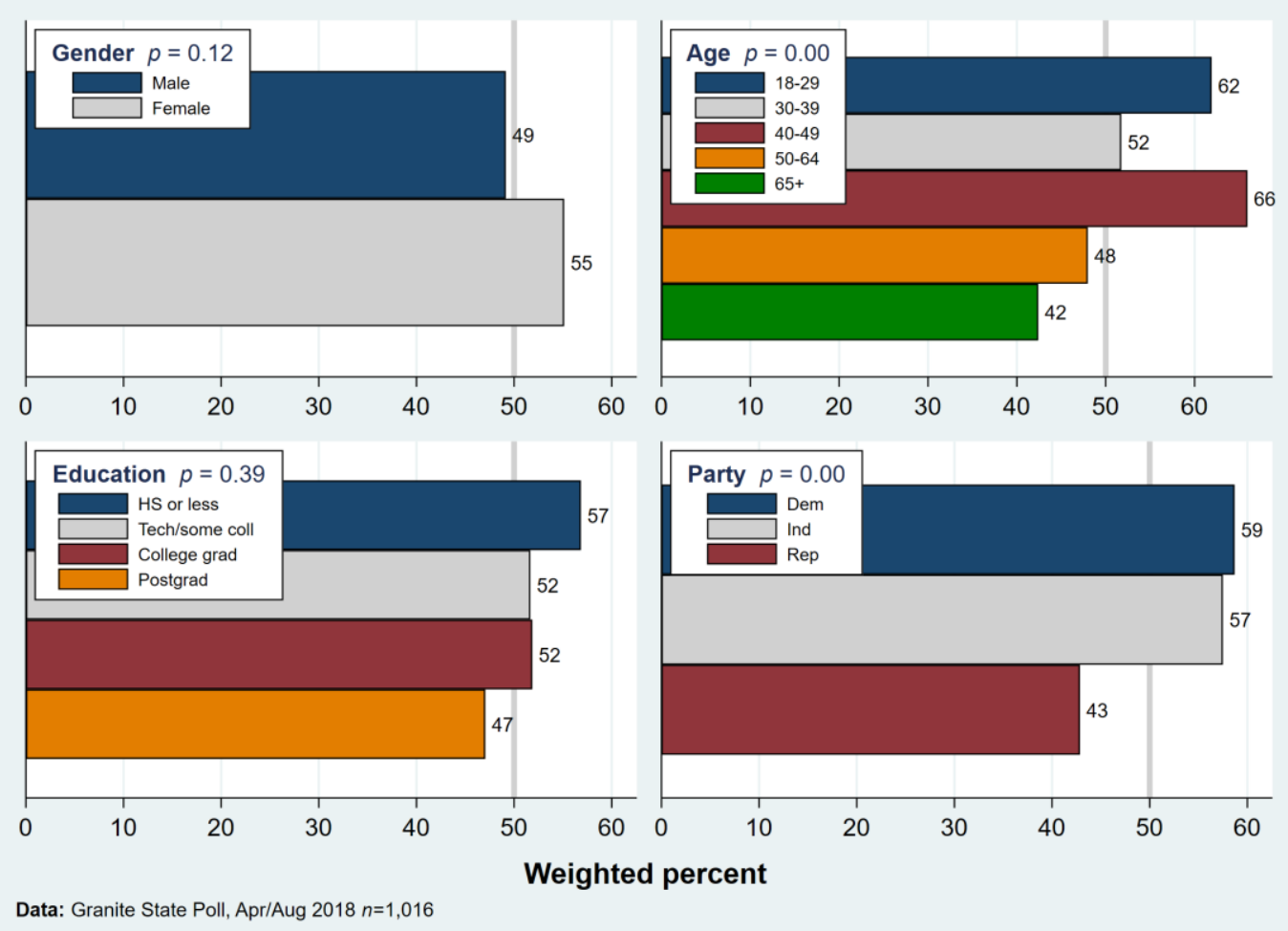

Figure 4. Respondents who prefer dam removal for benefits of fish and wildlife, over those want to keep dams for preservation of industrial history and those who responded don't know or gave no answer (dichotomized dependent variable).

Preferences to remove dams are broken down by respondent characteristics. $p$ values represent probabilities from $F$ tests for null hypothesis of predictors having no association with pro-dam removal responses.

\section{Lake- and pond-based recreation}

When asked about dam removal as opposed to keeping dams to maintain lake and pond-based recreational opportunities (damrec), responses bear some resemblance to results from the property and history tradeoff questions: party continues to have a strong effect and education the weakest (Figure 5). As usual, Democrats (50\%) and independents (46\%) are more likely to support removal than Republicans (34\%). In this tradeoff, gender also makes a difference: close to half of the female respondents support removal compared to only $38 \%$ of the males. Age also has significant effects, with older people (65+) least likely to support removal. 

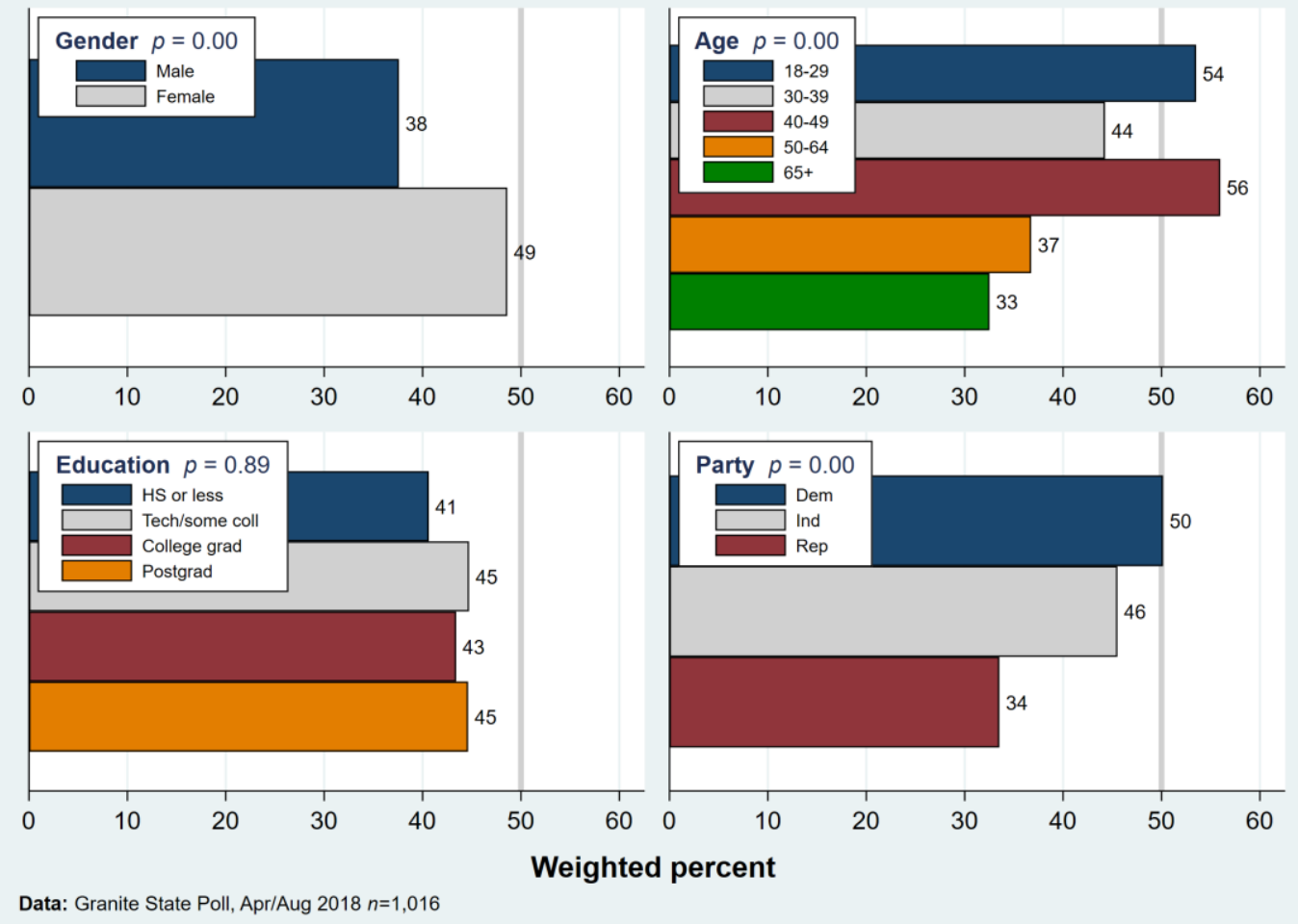

Figure 5. Respondents who prefer dam removal for benefits of fish and wildlife, over those who want to keep dams for lake or pond-based recreation and those who responded don't know or gave no answer (dichotomized dependent variable).

Preferences to remove dams are broken down by respondent characteristics. $p$ values represent probabilities from $F$ tests for null hypothesis of predictors having no association with pro-dam removal responses.

\section{Electricity generation from hydropower}

Differences by age, gender, and political party are all statistically significant at the $p<0.05$ level in the hydropower question (damhydro) (Figure 6). Education, however, has only weak effects. Younger and middle-aged respondents more often prefer dam removal over keeping the dam, when the alternative is hydropower. Political party affiliation again is the strongest predictor, with Democrats (39\%) and independents (37\%) more likely to prefer removal as compared to Republicans (24\%). Women also more often prefer dam removal, when the alternative is to keep dams for electricity generation. 

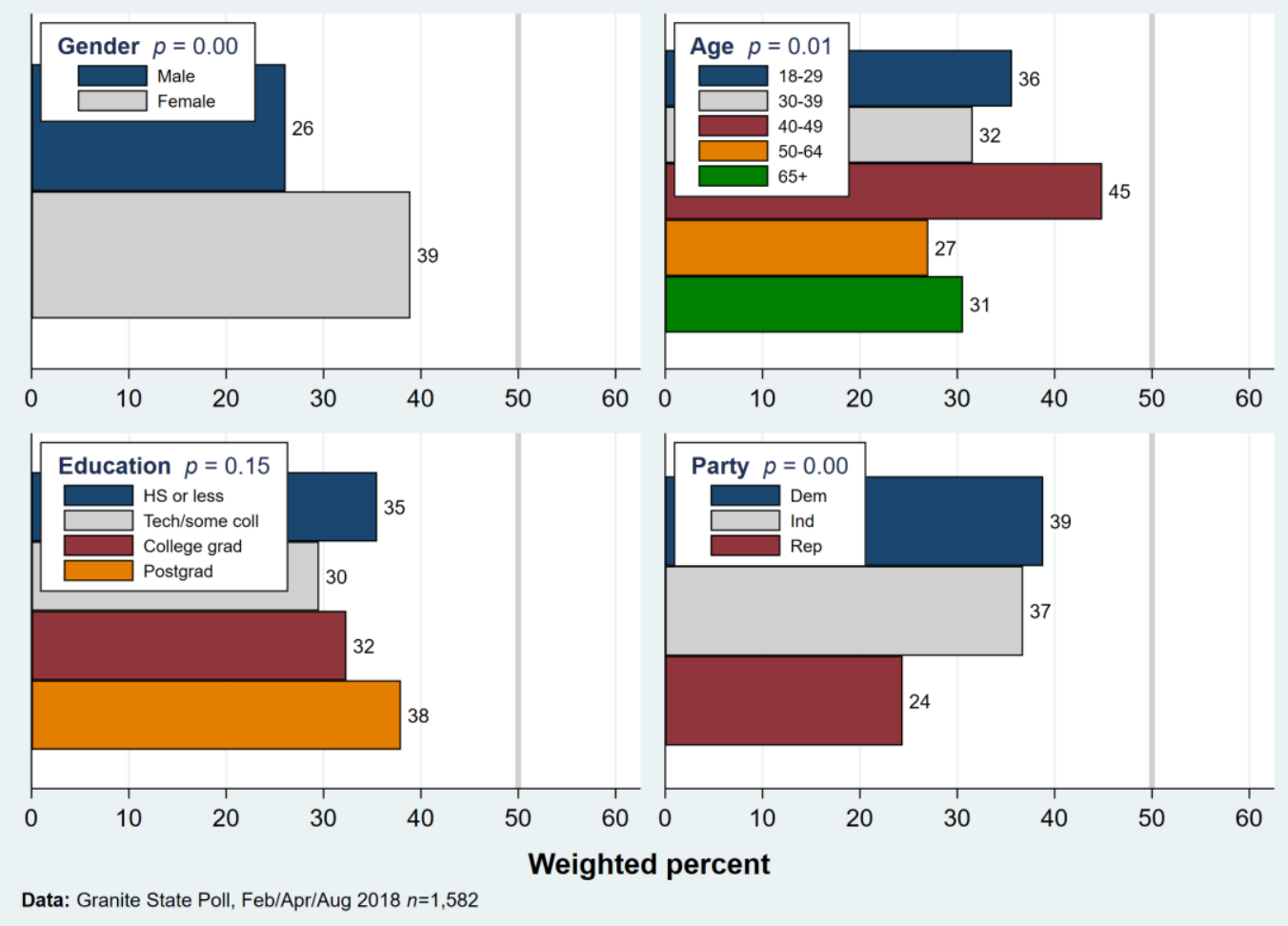

Figure 6. Respondents who prefer dam removal for benefits of fish and wildlife, over those who want to keep dams for electricity generation and those who respondent "don't know" or gave no answer (dichotomized dependent variable).

Preferences to remove dams are broken down by respondent characteristics. $p$ values represent probabilities from $F$ tests for null hypothesis of predictors having no association with pro-dam removal responses.

\section{Summary of bivariate results}

Overall, when comparing the results of the bivariate analyses (Leuchanka et al., 2019) for each of the four tradeoffs, it appears that age and party are relatively strong and consistent predictors of who is most likely to prefer dam removal. Party appears to be a dominant explanatory variable across all of our questions. Age exhibits somewhat weaker but consistent effects too, particularly in the lack of support for dam removal among people over age sixty-five. When the tradeoff is hydropower generation, support for dam removal drops below $50 \%$ for all age groups, but age effects are still clear: just $31 \%$ of people over the age of sixty-five support dam removal within the context of hydropower (damhydro question; Figure 6).

Although not always significant, the effects of gender lean in the same direction across all four of our tradeoffs: women are more likely than men to favor dam removal. The gender gap ranges from 13 points (39\% of women vs. $26 \%$ of men) on the hydropower tradeoff (Figure 6 ), to just three points ( $56 \%$ of women vs. $52 \%$ of men) on the property-values tradeoff (Figure 3 ). 
Interestingly, respondent's education, which plays an important role on many other environmental topics (Hamilton, 2011; McCright and Dunlap, 2011; Sovacool et al., 2018), makes no significant difference in any of these comparisons.

\section{Multivariate analysis}

Table 2 shows results from four multinomial logit regression models. The models predict support for dam removal over keeping dams for hydropower (damhydro), preservation of New Hampshire's industrial history (damhis), maintenance of lake- and pond-based recreation (damrec), and maintenance of waterfront property values (damprop) based on four predictors identified in Table 1: gender, education, age, and political party. We also tested for regional effects but found no systemic differences in responses between the various regions of New Hampshire (results not shown).

The multivariate analysis in Table 2 confirms most of the bivariate relationships, with the exception of age in the question addressing hydropower, where it is no longer significant. All four multinomial logit models (Table 2) estimate the effects of individual predictor variables when all other predictors in the model are held constant. Education remains a poor predictor of support for dam removal across all tradeoffs, after adjustments for the stronger effects of gender, age, and political party.

The first model in Table 2 (damhydro) shows that women are 82\% more likely (odds multiplied by 1.821) than men to favor removing dams, when the alternative is keeping them for hydropower. Political party affects these views as well: odds of favoring dam removal decline by $28 \%$ (multiplied by 0.724 ) with each step of political party, from Democrats to independents, then Republicans. Better-educated respondents are more likely to say they don't know, rather than to favor keeping dams, in response to this question (odds multiplied by 1.206 with each degree of education).

Table 2. Survey dates $-02 / 2018$ and $04 / 2018$ and $08 / 2018$. Predictors of dam decision alternative preferences and answers to four questions, with each question exploring different tradeoffs associated with keeping a dam.

Presented are relative risk ratios (RRR) from weighted multinomial regressions and $p$ values. Positive significant effects are in blue; negative significant effects are in red.

\begin{tabular}{|c|c|c|c|c|c|c|c|c|}
\hline \multicolumn{9}{|c|}{ Dependent variable } \\
\hline & \multicolumn{2}{|c|}{ damhydro } & \multicolumn{2}{|c|}{ damhis } & \multicolumn{2}{|c|}{ damrec } & \multicolumn{2}{|c|}{ damprop } \\
\hline Predictor & RRR & $p$ & RRR & $p$ & RRR & $p$ & RRR & $p$ \\
\hline (base) & \multicolumn{2}{|c|}{ Keep/hydro } & \multicolumn{2}{|c|}{ Keep/history } & \multicolumn{2}{|c|}{ Keep/recreation } & \multicolumn{2}{|c|}{ Keep/property values } \\
\hline & \multicolumn{2}{|c|}{ Remove } & \multicolumn{2}{|c|}{ Remove } & \multicolumn{2}{|c|}{ Remove } & \multicolumn{2}{|c|}{ Remove } \\
\hline $\operatorname{Gender}(F)$ & 1.821451 & 0.000 & 1.444715 & 0.075 & 1.897504 & 0.002 & 1.340903 & 0.170 \\
\hline Age & .9941032 & 0.175 & .9857421 & 0.012 & .9787474 & 0.000 & .9824963 & 0.005 \\
\hline Education & 1.051349 & 0.483 & .8816404 & 0.161 & 1.075209 & 0.424 & 1.072429 & 0.448 \\
\hline \multirow[t]{2}{*}{ Party } & .724009 & 0.000 & .7107359 & 0.002 & .7245111 & 0.003 & .6259391 & 0.000 \\
\hline & \multicolumn{2}{|c|}{$\overline{\mathrm{DK} / \mathrm{NA}}$} & \multicolumn{2}{|c|}{ DK/NA } & \multicolumn{2}{|c|}{ DK/NA } & \multicolumn{2}{|c|}{ DK/NA } \\
\hline Gender $(F)$ & 1.393459 & 0.054 & 1.199 & 0.452 & 1.666871 & 0.025 & 1.490356 & 0.119 \\
\hline
\end{tabular}




\begin{tabular}{l|cl|cc|cc|cc} 
Age & 1.006579 & 0.176 & 1.010145 & 0.159 & .999448 & 0.935 & 1.009694 & 0.206 \\
Education & 1.205492 & 0.017 & 1.121372 & 0.298 & 1.062824 & 0.555 & 1.02906 & 0.808 \\
Party & .8767932 & 0.170 & .9442563 & 0.668 & .9114907 & 0.464 & .7978738 & 0.101 \\
\hline Estimation sample & 1,446 & & 927 & & 927 & & 927 & \\
$F$ statistic & 6.15 & 0.000 & 4.42 & 0.000 & 5.54 & 0.000 & 5.55 & 0.000 \\
\hline
\end{tabular}

Subsequent columns in Table 2 show the corresponding results for other dam-tradeoff questions. Women are more likely than men to favor dam removal across all tradeoffs, although these gender effects are statistically significant only with regard to the hydropower and recreation tradeoffs. Conversely, older respondents are less likely to favor dam removal across all tradeoffs; such age effects are significant with regard to history, recreation, and property values tradeoffs. Respondent education exhibits no consistent effects, with none of the relative risk ratios significantly different from 1.0 (no effect).

Political party exhibits consistent effects: for each tradeoff, independents are less likely than Democrats, and Republicans less likely than independents, to favor keeping the dams. These political effects are statistically significant, and have similar strength, for all tradeoffs.

The lower panels of Table 2 contrast "don't know" responses with being in favor of keeping the dams. Only two significant effects are seen: better educated respondents are more likely to say "don't know" than they are to favor keeping dams for hydropower; and female respondents are less likely to say "don't know" than they are to favor keeping dams for recreation.

In Figures 7 and 8, a set of margins plots calculated from models in Table 2 provides visualization of these multivariate effects. For example, for the hydropower question, females (Figure 8D) across all party affiliations are more likely to prefer to remove dams than to keep dams, whereas age (Figure 8E) and education (Figure 8F) have no statistically significant effects on the probability of choosing dam removal. Political party affiliation predicts people's preferences in the hydropower question, with highest probability of choosing dam removal among Democrats and lowest among Republicans (Figure 8D-F). 

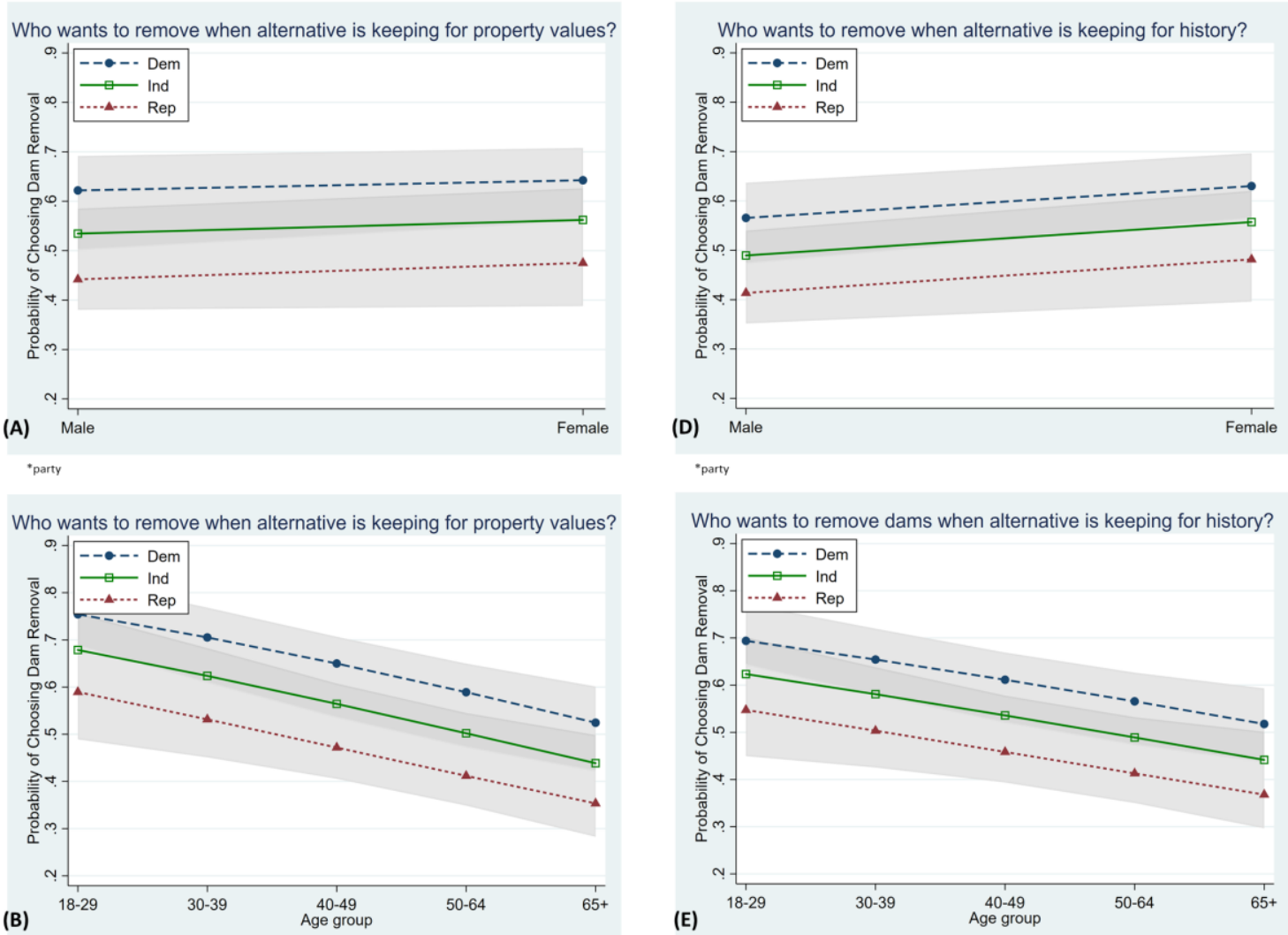

(B)

*age, party

$$
\text { "party }
$$

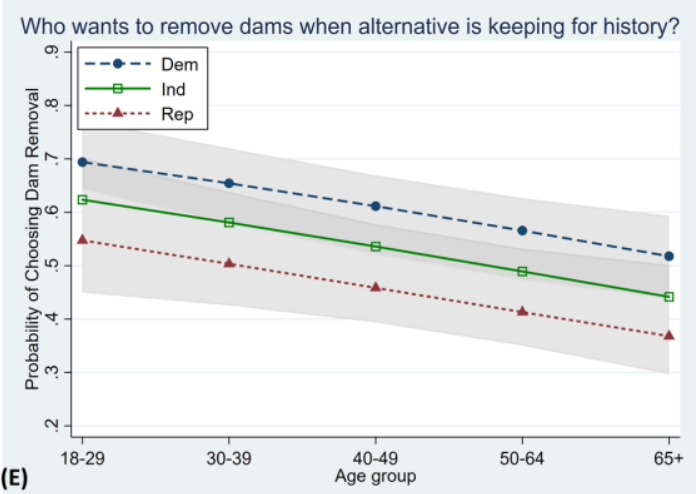

-age, party
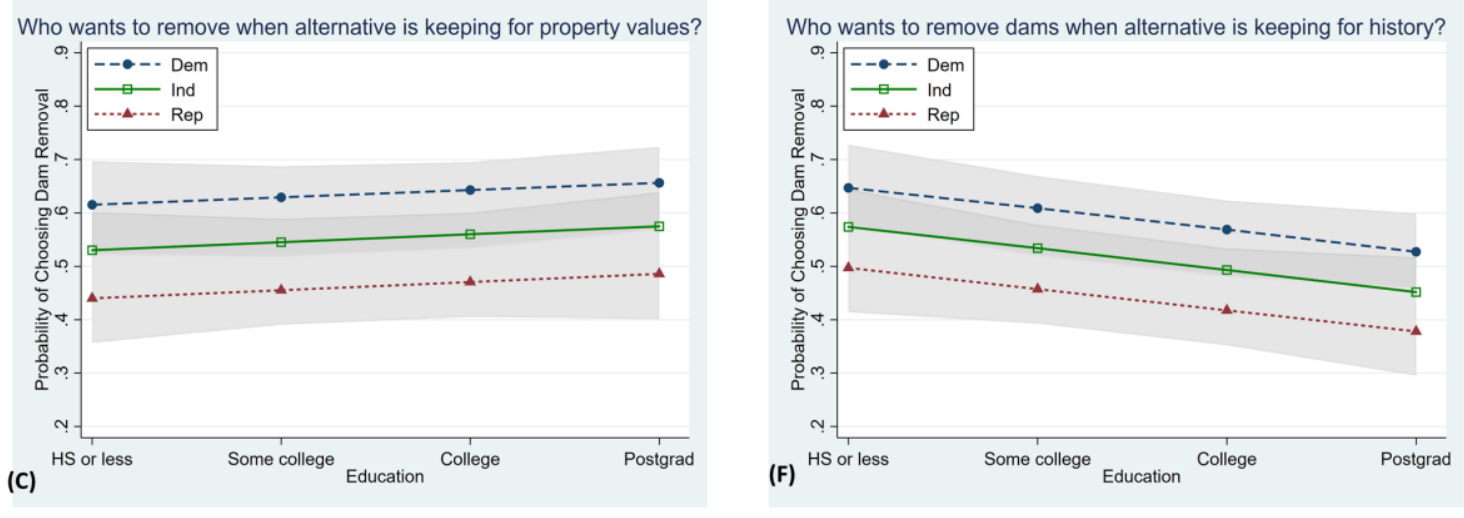

Figure 7. Predicted probability of "remove dams for benefits of fish and wildlife" response for questions concerning waterfront property values and industrial history (independent variables).

Questions are centered around the following tradeoffs: waterfront property values (damprop) (A-C), industrial history (damhis) (D-F). Probabilities are calculated from the model in Table 2 and incorporate other predictors in the model. Asterisks with affiliated variable names indicates statistically significant results at $p<0.05$ (consistent with those shown in Table 2). 

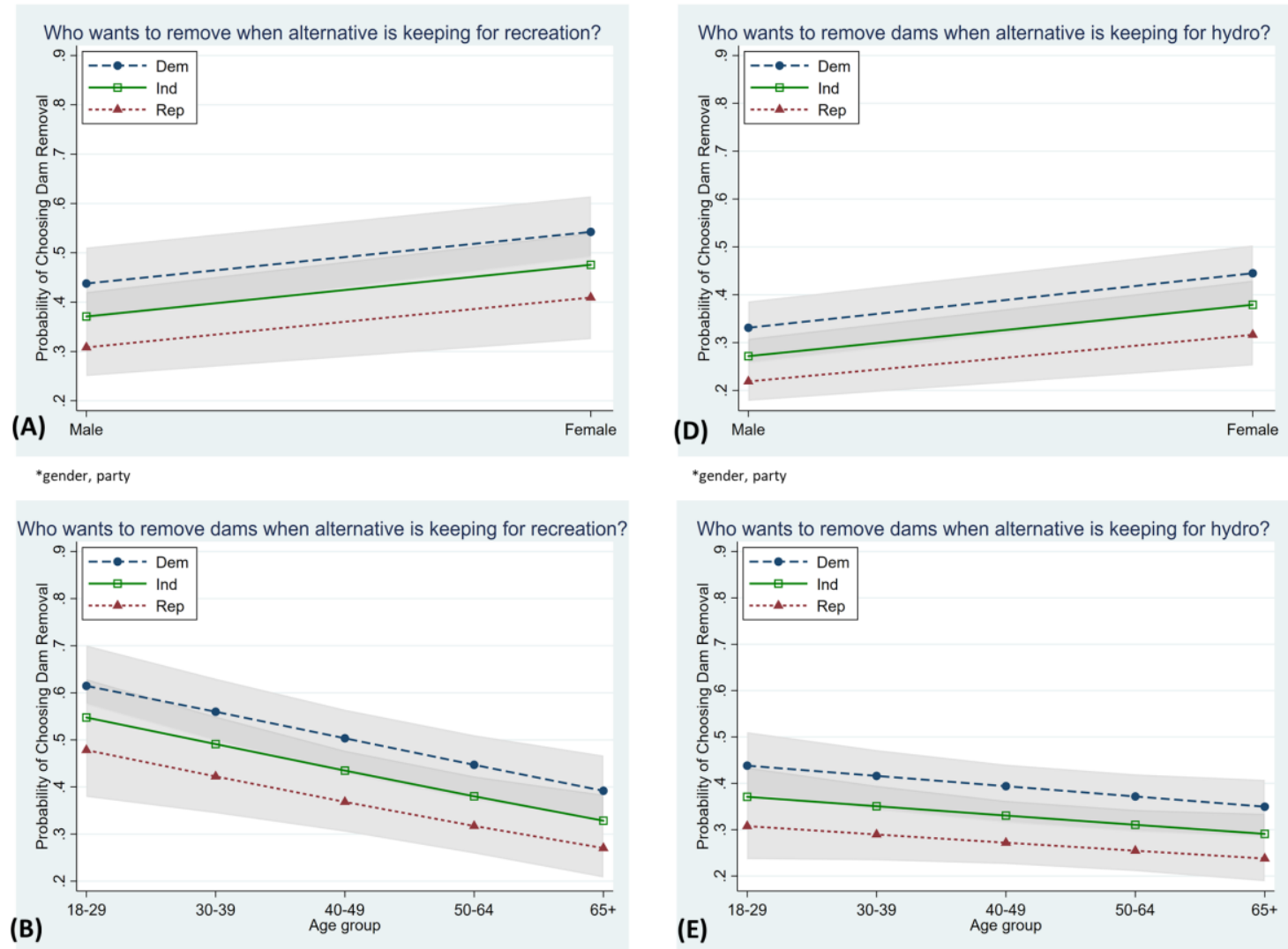

*age, party

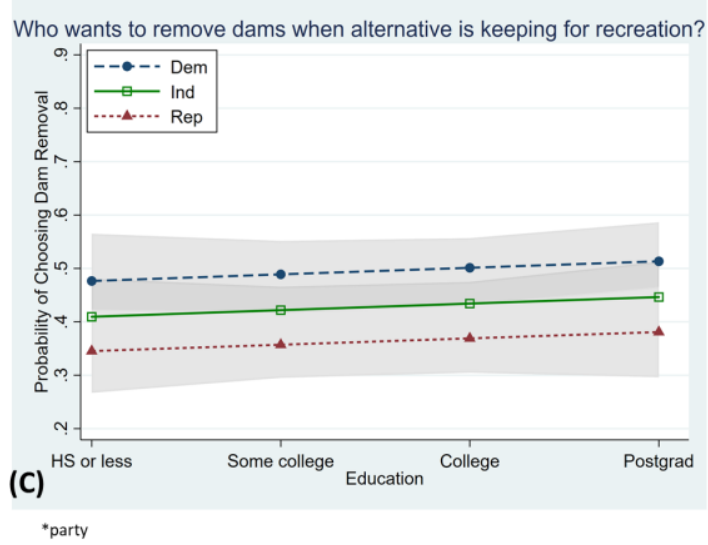

*party

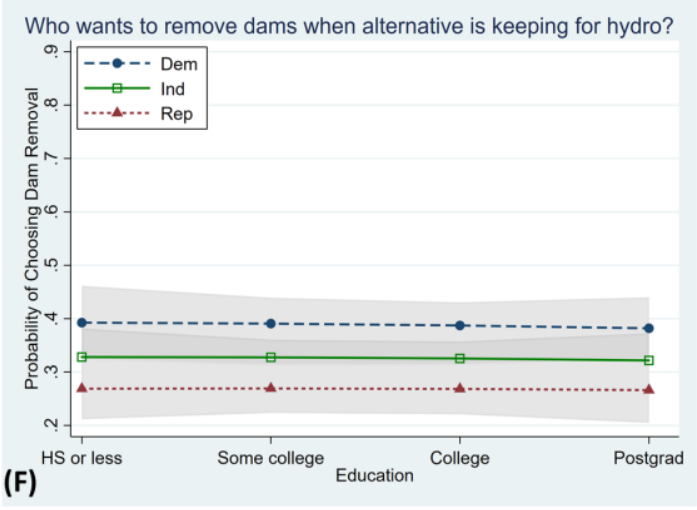

"party

Figure 8. Predicted probability of "remove dams for benefits of fish and wildlife" response for questions concerning recreation and hydropower (independent variables).

Questions are centered around the following tradeoffs: lake- and pond-based recreation (damrec) (A-C), and electricity generation from hydropower (damhydro) (D-F). Probabilities are calculated from the model in Table 2 and incorporate other predictors in the model. Asterisks with affiliated variable names indicates statistically significant results at $p<0.05$ (consistent with those shown in Table 2).

Responses to one (hydropower; Figure 8D-F) of the four tradeoff questions indicate more respondents prefer to keep dams than prefer to remove dams. Other tradeoffs elicit more pro- 
removal preferences: waterfront property values (Figure 7A-C), (industrial history (Figure 7DF), and recreation (Figure 8A-C). Political party affiliation is a constant predictor across all four tradeoffs, regardless of whether they provoke more pro-removal or pro-keep responses.

The effect of respondents' age continues to influence dam removal preference in the question concerning industrial history (Figure 7D-F), with younger people more likely to prefer removal. Relationships in the question exploring flatwater recreation behave similarly to relationships observed for the question about hydropower. Females and Democrats are most likely to prefer dam removal instead of keeping dams for lake-based recreation. The recreation-specific question is also the only question where a respondent's age, gender, and political party all have strong explanatory power (Table 2), suggesting that this tradeoff could be the most socially divisive; only two of these three predictor variables have significant effects in the other four questions. The questions exploring preferences for dam removal as opposed to keeping dams for maintenance of waterfront property values or industrial history are not impacted by gender (unlike the other three questions) (Figure 7A and 7D; Table 2). A respondent's level of education is the only predictor variable that has no significant exploratory power or systematic effect in any of the questions (Table 2; Figure 7C and 7F; Figures 8C and 8F).

\section{Discussion}

In addition to its empirical contribution, this research contributes to research and discussions on decisions about freshwater systems in three ways.

First, our research provides insight into dam decisions in the New Hampshire context. In general, public interest in dam removal is high, but varies depending on the benefit provided by the dam. While there is significant interest in keeping dams for generating hydropower, more respondents wanted to remove dams for ecosystem benefits than keep dams for other commonly heard benefits: maintaining lake- and pond-based recreation, preserving industrial history and waterfront property values. These results indicate that even in a region where industrial dams continue to drive current popular uses of land and water resources, public interest in dam removal for ecosystem restoration is high. The high "don't know" or no answer response rate, as compared to rates observed in previous environment-related public opinion surveys (Hamilton, 2012), could be due to lower general awareness about dam-related issues relative to other environmental issues (e.g. climate change). Recognizing that every dam decision is unique and that an individual's preferences may differ when confronted with a decision about a specific dam as compared to dams in general, our results provide information about the general public's preferences, which can complement information provided in local forums to discuss decisions about specific dams. Given the significant implications for New Hampshire's public resources, in order to steward public resources wisely in the public interest, decisions about dams should include dam removal as a decision option. Future research could evaluate whether New Hampshire survey responses about dam decisions resemble regional and national preferences. Additionally, future studies could test identical questions with different arguments for removing dams, such as safety. 
Second, demographic factors shape public preferences for dam decisions. When comparing results of multinomial models for all four questions (Figures 7 and 8; Table 2) exploring different tradeoffs associated with dams, we see some clear trends. In general, women, Democrats or independents, and young or middle-aged adults are more likely to favor removing dams. Level of formal education does not much affect dam management preferences. Small to moderate gender differences in the same direction, women more likely to favor dam removal, occur on all four questions.

Overall, years of previous research has demonstrated that pro-environmental views and concerns are highest among female, younger, liberal leaning, and better educated respondents (Hamilton et al., 2019). In our study, the effect of age in the waterfront property values related question might partially reflect more older people owning waterfront properties. Our findings about gender, even where results are not statistically significant, are consistent with other studies which found women to align with more pro-environmental views as compared to men (McCright and Xiao, 2014). On the other hand, our study found no significant effects from education, in contrast with the patterns seen for many other environment-related topics (Jones and Dunlap, 1992; Hamilton et al., 2010), including climate change (Hamilton, 2012) and electric vehicles within the context of carbon emissions and sustainability transitions (Sovacool et al., 2018). Previous studies generally found environmental concerns rising with education (Van Liere and Dunlap, 1980; Jones and Dunlap, 1992), particularly in those who hold undergraduate and postgraduate degrees (Sovacool et al., 2018). However, we do not observe this trend when asking New Hampshire residents about their preferences for dam removal, suggesting that education is not a key factor regarding people's preferences about dam removal.

The dominant effects of partisan identity seen in these analyses are repeated if, instead of party, we use self-reported ideology (not shown). Similarly, parallel results from using either party or ideology have been reported on other environment-related topics as well (e.g., climate change and renewable energy in Hamilton et al., 2019). Political effects on our dam-removal questions parallel findings from countless studies of other general or specific environment-related issues (Hamilton et al., 2010; McCright and Dunlap, 2011; Hamilton and Saito, 2015). To our knowledge, this is the first time such patterns have been observed in connection with dam removal decision-making. The finding that Democrats and independents are more likely to support dam removal than Republicans does not raise new obstacles for such decision-making, but suggests one obstacle that already was there, and must be taken into account. From this we can infer that elements of partisan ideology and sociopolitical identity will probably infuse seemingly local, practically-oriented discussions about the need for dam removal. Given the dominant role of political identity as a factor in dam-removal opinions, this should be explored further in future research. Well-founded information about the pros and cons of local dam removal almost certainly is quite limited among the general public, so there is great scope for accessible information and outreach. Latent partisan differences could subject such outreach to information-filtering processes such as biased assimilation, well known in other fields, whereby people preferentially retain information that confirms their prejudices (Munro and Ditto, 1997; 
Corner et al., 2012), and choose media sources that agree (Bolin and Hamilton, 2018). Results could inform the design, for different audiences, of information about dam decision making.

These findings indicate that conflicts over dams are not only conflicts between pro-removal and pro-dam advocates, but are also part of other identity conflicts. For example, older people, Republicans, and males tend to prefer to keep dams and may therefore see dam maintenance as a wise use of public resources, while younger people, Democrats or independents, and females are likely to prefer to remove the dam and prioritize other uses of public funding. Recognizing that preferences change over time and our findings provide only a snapshot of preferences, it is nevertheless important to consider the importance of identity, specifically of age, gender and political party differences, in analyses of the politics of dam decisions, removal and river restoration. Other research into the influence of identity on environmental preferences indicates that identity is at least as important as education in affecting public opinion (Hamilton et al., 2015; Hamilton et al., 2019). Interested parties, such as dam removal advocates and hydropower advocates, may therefore want to consider targeted communication strategies for specific audiences based on an improved understanding of the values that motivate them.

Third, our findings shed light on the importance of considering demographic characteristics to ensure that processes for public participation are representative. Since demographic characteristics are predictors of dam preferences, forums dominated by particular demographics are unlikely to represent fully the public interest. Regardless, organizers of public forums and policy makers who use the input to inform dam decisions need to pay attention to the demographics of who participates to avoid marginalizing voices that are already less heard. For example, anecdotal evidence from attending a variety of public meetings in New Hampshire shows participants are more likely to be older. According to our findings, the views expressed at public meetings are therefore more likely to be in favor of keeping dams. Organizers of public meetings may want to consider strategies to ensure representation of different genders, ages and political party. For example, providing childcare can make it easier for younger people with small children to attend events. Varying the kind of opportunities to provide input, such as using online surveys or forums at schools, can also be used to complement typical town hall meetings to attract more diverse participants and better represent the public interest.

Our findings also support the use of public opinion polling to inform deliberative processes, providing support for interesting possibilities to combine the two to inform dam decisions. Public opinion polling is one tool that can supplement input heard at public meetings, such as local town meetings about dam decisions, and arguably result in more democratic decision processes and equitable outcomes (Fishkin, 2011). Randomized public surveys around critical issues concerning communities are particularly important from an equity standpoint because they provide voice to residents who are not able to attend town meetings. A relatively quick telephone survey, such as the one implemented in this study, can provide these residents with an opportunity to participate in their local democratic process without having to take hours out of their day to attend local meetings. While public surveys only provide a "temporary snapshot of public opinion," which may be based on little information (Fishkin, 2011) or interest, they also contribute toward identifying where the public stands around a particular issue (Renn, 2015). 
Increased public participation is particularly important because decisions around dams often require the use of public funds, so engaging a more diverse and representative group of residents in the decision process helps ensure that taxpayers' contributions are properly allocated toward community needs.

The findings presented in this paper are an attempt to gain a basic understanding of New Hampshire residents' preferences for dam removal, and in retrospect, their underlying motivating values. This study therefore helps achieve value competence (Dietz, 2013) by using scientific analysis to expand our understanding of public values to inform public deliberation and wise decisions about the future of dams and freshwater systems.

\section{References}

Arnstein SR. 1969. A Ladder Of Citizen Participation. Journal of the American Planning Association 35(4): 216-224. doi: 10.1080/01944366908977225

Batie SS. 2008. Wicked problems and applied economics. American Journal of Agricultural Economics 90(5): 1176-1191. doi: 10.1111/j.1467-8276.2008.01202.x

Bolin JL, Hamilton LC. 2018. The News You Choose: news media preferences amplify views on climate change. Environmental Politics 00(00): 1-22. Routledge. doi:

10.1080/09644016.2018.1423909

Born SM, Genskow KD, Filbert TL, Hernandez-Mora N, Keeper ML, White KA. 1998. Socioeconomic and institutional dimensions of dam removals: The Wisconsin experience. Environmental Management 22(3): 359-370. doi: 10.1007/s002679900111

Burroughs BA, Hayes DB, Klomp KD, Hansen JF, Mistak J. 2010. The Effects of the Stronach Dam Removal on Fish in the Pine River, Manistee County, Michigan. Transactions of the American Fisheries Society 139(5): 1595-1613. doi: 10.1577/T09-056.1

Clark WC, van Kerkhoff L, Lebel L, Gallopin GC. 2016. Crafting usable knowledge for sustainable development. Proceedings of the National Academy of Sciences 113(17): 4570-4578. doi: 10.1073/pnas.1601266113

Corner A, Whitmarsh L, Xenias D. 2012. Uncertainty, scepticism and attitudes towards climate change: Biased assimilation and attitude polarisation. Climatic Change 114(3-4): 463-478. doi: 10.1007/s10584-012-0424-6

Creighton JL. 2005. The Public Participation Handbook: Making Better Decisions Through Citizen Involvement. 1st ed. San Francisco, CA: John Wiley \& Sons, Inc.

Creswell JW. 2014. Quantitative Methods. In: Research Design: Qualitative, Quantitative, and Mixed Methods Approaches4th ed. Thousand Oaks, CA: SAGE Publications. p. 155-182.

Cronon W. 2003. Changes in the Land: Indians, Colonists, and the Ecology of New England. Revised. New York: Hill and Wang.

Data Discovery Center. 2019. New England Dams Database. Available at http://ddcdams.sr.unh.edu/. Accessed 2019 Mar 4. 
Diessner NL, Ashcraft CM. n.d. People and Conflicts in Dammed New England Landscapes: a Stakeholder Assessment. Manuscript in Preparation, in press.

Diessner NL, Ashcraft CM, Gardner KH, Hamilton LC. 2019a. Granite State Poll \#69 - Client Poll. Durham, NH: Figshare. doi: https://doi.org/10.6084/m9.figshare.10284272

Diessner NL, Ashcraft CM, Gardner KH, Hamilton LC. 2019b. Granite State Poll \#70 - Political Poll. Durham, NH: Figshare. doi: https://doi.org/10.6084/m9.figshare.10284284

Diessner NL, Ashcraft CM, Gardner KH, Lawrence C. Hamilton. 2019. Granite State Poll \# 68 Client Poll. Durham, NH: Figshare. doi: https://doi.org/10.6084/m9.figshare.10284197

Dietz T. 2013. Bringing values and deliberation to science communication. Proceedings of the National Academy of Sciences of the United States of America 110: 14081-14087. doi: 10.1073/pnas.1212740110

Dietz T, Fitzgerald A, Shwom R. 2005. Environmental Values. Annual Review of Environment and Resources 30: 335-372. doi: 10.1016/j.jaci.2012.05.050

Dowley R, Houghton M, Mitchell C, Villalba S. 2019. Up Against the Wall: Barriers and Incentives for Dam Removal. Available at https://as.tufts.edu/uep/sites/all/themes/asbase/assets/documents/fieldProjectReports/2019/upagainst-the-wall.pdf.

Dunlap RE, Xiao C, McCright AM. 2001. Politics and Environmental in America: Partisan and Ideological Cleavages in Public Support for Environmentalist. Environmental Politics 10(4): 2348.

Fishkin JS. 2011. When the People Speak: Deliberative Democracy and Public Consultation. Reprint. New York: Oxford University Press. doi:

10.1093/acprof:osobl/9780199604432.001.0001

Fox CA, Magilligan FJ, Sneddon CS. 2016. "You kill the dam, you are killing a part of me": Dam removal and the environmental politics of river restoration. Geoforum 70: 93-104. Elsevier Ltd. doi: 10.1016/j.geoforum.2016.02.013

Gierisch JM, Reiter PL, Rimer BK, Brewer NT. 2010. Standard definitions of adherence for infrequent yet repeated health behaviors. American Journal of Health Behavior 34(6): 669-679.

Gleick PH. 2018. Transitions to freshwater sustainability. Proceedings of the National Academy of Sciences of the United States of America 115(36): 8863-8871. doi: 10.1073/pnas.1808893115

Gold AJ, Addy K, Morrison A, Simpson M. 2016. Will dam removal increase nitrogen flux to estuaries. Water (Switzerland) 8(11). doi: 10.3390/w8110522

Goodby RG, Tremblay S, Bouras E. 2014. The Swanzey Fish Dam: A Large, Precontact Native American Stone Structure In Southwestern New Hampshire. Northeast Anthropology 81-82: 122.

Graf WL. 1999. Dam nation: A geographic census of American dams and their large-scale hydrologic impacts. Water Resources Research 35(4): 1305-1311. doi: 10.1029/1999WR900016

Guagnano GA, Markee N. 1995. Regional differences in the sociodemographic determinants of environmental concern. Population and Environment: A Journal of Interdisciplinary Studies 17(2): 135-149. doi: 10.1007/BF02208385 
Hage M, Leroy P, Petersen AC. 2010. Stakeholder participation in environmental knowledge production. Futures 42(3): 254-264. Elsevier Ltd. doi: 10.1016/j.futures.2009.11.011

Hamilton LC. 2011. Education, politics and opinions about climate change evidence for interaction effects. Climatic Change 104(2): 231-242. doi: 10.1007/s10584-010-9957-8

Hamilton LC. 2012. Did the Arctic Ice Recover? Demographics of True and False Climate Facts. Weather, Climate, and Society 4(4): 236-249. doi: 10.1175/WCAS-D-12-00008.1

Hamilton LC. 2013. Statistics with Stata: Version 12. 8th ed. Boston: Brooks/Cole, Cengage Learning. Available at https://www.stata.com/bookstore/statistics-with-stata/.

Hamilton LC. 2016. Where is the North Pole? An election-year survey on global change. Durham, NH. Available at https://scholars.unh.edu/carsey/285/.

Hamilton LC, Colocousis CR, Duncan CM. 2010. Place effects on environmental views. Rural Sociology 75(2): 326-347. doi: 10.1111/j.1549-0831.2010.00013.x

Hamilton LC, Hartter J, Bell E. 2019. Generation gaps in US public opinion on renewable energy and climate change. PLoS One 14(7). doi: 10.1371/journal.pone.0217608

Hamilton LC, Hartter J, Lemcke-Stampone M, Moore DW, Safford TG. 2015. Tracking public beliefs about anthropogenic climate change. PLOS ONE 10(9): 1-15. doi:

10.1371/journal.pone.0138208

Hamilton LC, Saito K. 2015. A four-party view of US environmental concern. Environmental Politics 24(2): 212-227. doi: 10.1080/09644016.2014.976485

Hamilton LC, Wake CP, Hartter J, Safford TG, Puchlopek AJ. 2016. Flood Realities, Perceptions and the Depth of Divisions on Climate. Sociology 50(5): 913-933. doi:

$10.1177 / 0038038516648547$

Hosseini Shakib I. 2019. Dams in New Hampshire, USA. doi: 10.6084/m9.figshare.10295264.v1

Johnson SE, Graber BE. 2002. Enlisting the social sciences in decisions about dam removal. BioScience 52(8): 731. doi: 10.1641/0006-3568(2002)052[0731:ETSSID]2.0.CO;2

Jones RE, Dunlap RE. 1992. The Social Bases of Environmental Concern: Have They Changed Over Time? Rural Sociology. doi: 10.1111/j.1549-0831.1992.tb00455.x

Klineberg SL, McKeever M, Rothenbach B. 1998. Demographic predictors of environmental concern: It does make a difference how it's measured. Social Science Quarterly 79(4): 734-753.

Leuchanka N, Ashcraft CM, Gardner K, Hamilton LC. 2019. What to Do With Dams: An Assessment of Public Opinion to Inform the Debate in New Hampshire. Durham, NH. Available at https://scholars.unh.edu/cgi/viewcontent.cgi?article=1375\&context=carsey.

Van Liere KD, Dunlap RE. 1980. The Social Bases of Environmental Concern: A Review of Hypotheses, Explanations and Empirical Evidence. Public Opinion Quarterly 44: 181-197.

Limburg KE, Waldman JR. 2009. Dramatic Declines in North Atlantic Diadromous Fishes. BioScience 59(11): 955-965. doi: 10.1525/bio.2009.59.11.7

Lindloff SD. 2003. Institutionalizing the option of dam removal: The New Hampshire initiative. Water Science and Technology 48(7): 9-16. 
Magilligan FJ, Graber BE, Nislow KH, Chipman JW, Sneddon CS, Fox CA. 2016. River restoration by dam removal: Enhancing connectivity at watershed scales. Elementa: Science of the Anthropocene 4: 000108. doi: 10.12952/journal.elementa.000108

Magilligan FJ, Sneddon CS, Fox CA. 2017. The Social, Historical, and Institutional Contingencies of Dam Removal. Environmental Management 59(6): 982-994. Springer US. doi: $10.1007 / \mathrm{s} 00267-017-0835-2$

McCool SF, Guthrie K. 2001. Mapping the dimensions of successful public participation in messy natural resources management situations. Society and Natural Resources 14(4): 309-323. doi: $10.1080 / 713847694$

McCright AM, Dunlap RE. 2011. The Politicization Of Climate Change And Polarization In The American Public's Views Of Global Warming, 2001-2010. Sociological Quarterly 52(2): 155194. doi: 10.1111/j.1533-8525.2011.01198.x

McCright AM, Xiao C. 2014. Gender and Environmental Concern: Insights from Recent Work and for Future Research. Society and Natural Resources 27(10): 1109-1113. doi:

10.1080/08941920.2014.918235

Miller TR, Wiek A, Sarewitz D, Robinson J, Olsson L, Kriebel D, Loorbach D. 2014. The future of sustainability science: A solutions-oriented research agenda. Sustainability Science 9(2): 239246. doi: 10.1007/s11625-013-0224-6

Mullens JB, Wanstreet V. 2010. Using willingness-to-pay surveys when assessing dam removal: A New Hampshire case study. Geographical Bulletin - Gamma Theta Upsilon 51(2): 97-110.

Munro GD, Ditto PH. 1997. Biased Assimilation, Attitude Polarization, and Affect in Reactions to Stereotype-Relevant Scientific Information. Personality and Social Psyschology Bulletin 23(6): 636-653.

NH Department of Environmental Services. 2008. New Hampshire Water Resources Primer. Concord. Available at https://www.des.nh.gov/organization/divisions/water/dwgb/wrpp/documents/water_resources_pr imer.pdf.

O'Connor JE, Duda JJ, Grant GE. 2015. 1000 Dams Down and Counting. Science 348(6234): 496-497. doi: 10.1126/science.aaa9204

Opperman JJ, Royte J, Banks J, Day LR, Apse C. 2011. The Penobscot River, Maine, USA: A basin-scale approach to balancing power generation and ecosystem restoration. Ecology and Society 16(3): 04. doi: 10.5751/ES-04117-160307

Poff NL, Hart DD. 2002. How Dams Vary and Why It Matters for the Emerging Science of Dam Removal. BioScience 52(8): 659. doi: 10.1641/0006-3568(2002)052[0659:HDVAWI]2.0.CO;2

Renn O. 2015. Stakeholder and Public Involvement in Risk Governance. International Journal of Disaster Risk Science 6(1): 8-20. doi: 10.1007/s13753-015-0037-6

Renn O, Schweizer PJ. 2009. Inclusive risk governance: Concepts and application to environmental policy making. Environmental Policy and Governance 19(3): 174-185. doi: 10.1002/eet.507 
Rittel HWJ, Webber MM. 1973. Dilemmas in a general theory of planning. Policy Sciences 4(2): 155-169. doi: 10.1007/BF01405730

Roy SG, Uchida E, de Souza SP, Blachly B, Fox E, Gardner K, Gold AJ, Jansujwicz J, Klein S, McGreavy B, et al. 2018. A multiscale approach to balance trade-offs among dam infrastructure, river restoration, and cost. Proceedings of the National Academy of Sciences(November): 6. doi: 10.1073/pnas.1807437115

Scala DJ, Smith AE. 2008. Does the Tail Wag the Dog? Early Presidential Nomination Polling in New Hampshire and the U.S. The American Review of Politics 28: 401-424.

Song C, Gardner KH, Klein SJW, Souza SP, Mo W. 2018. Cradle-to-grave greenhouse gas emissions from dams in the United States of America. Renewable and Sustainable Energy Reviews 90(July 2017): 945-956. Elsevier Ltd. doi: 10.1016/j.rser.2018.04.014

Sovacool BK, Kester J, Noel L, de Rubens GZ. 2018. The demographics of decarbonizing transport: The influence of gender, education, occupation, age, and household size on electric mobility preferences in the Nordic region. Global Environmental Change 52(January): 86-100. doi: 10.1016/j.gloenvcha.2018.06.008

The General Court of New Hampshire, Fish and Game Commission. 2004. Pub. L. No. RSA 206:4-a(I). U.S.A. Available at http://www.gencourt.state.nh.us/rsa/html/xviii/206/206-mrg.htm.

UNH Survey Center. 2020a. Granite State Poll \#68 (Client Poll) - Technical Report. Durham, NH: Figshare. doi: https://doi.org/10.6084/m9.figshare.12312284.v1

UNH Survey Center. 2020b. Granite State Poll \#69 (Client Poll) - Technical Report. Durham, NH: Figshare. doi: https://doi.org/10.6084/m9.figshare.12312497.v1

UNH Survey Center. 2020c. Granite State Poll \#70 (Political Poll) - Technical Report. Durham, NH: Figshare. doi: https://doi.org/10.6084/m9.figshare.12313577.v1

Xiao C, McCright AM. 2007. Environmental concern and sociodemographic variables: A study of statistical models. Journal of Environmental Education 38(2): 3-13. doi:

10.3200/JOEE.38.1.3-14 


\section{Contributions}

NLD, CMA, KG, LCH contributed to research conceptualization. $\mathrm{LCH}$ developed the data analysis methodology. NLD and LCH contributed to data curation, formal analysis and data visualization. NLD developed the initial draft with significant writing contributions from CMA, LCH and KG. All participated equally in revisions. CMA and KG contributed to funding acquisition. All approved the submitted version for publication.

\section{Acknowledgements}

The Survey Center at the University of New Hampshire conducted all the interviews for the Granite State Poll. Iman Hosseini Shakib created the map in Figure 1. The authors previously published Figures 2-6 in a policy brief. The authors would like to credit the Carsey School of Public Policy for allowing republication of these figures. The authors would like to thank the anonymous reviewers for their thoughtful and helpful feedback.

\section{Funding information}

This work was supported by a National Science Foundation EPSCoR award \#IIA-1539071. The funders had no role in study design, data collection and analysis, decision to publish, or preparation of the manuscript.

\section{Competing interests}

The authors have declared that no competing interests exist.

\section{Data accessibility statement}

The data used in our analysis is available in a public repository on Figshare and can be accessed via the following link: https://doi.org/10.6084/m9.figshare.11920740.v2 . The entire Figshare collection consisting of survey questionnaires, survey technical reports, and the dataset can be accessed via the following link: https://doi.org/10.6084/m9.figshare.c.4835607.v1. 